\title{
Health status of Chinese Employees from China Seismological Bureau of Beijing Area and the Research of Interventions
}

\author{
QIAO JIA ${ }^{1, a}$, LI RUIHENG ${ }^{2, b}$ and HONG WANG ${ }^{3, c}$ \\ 1,2,3 Institute of Disaster Prevention Science and Technology, Yanjiao, East of \\ Beijing,101601,China \\ a QIAOJIA929@yeah.net
}

Keywords: China seismological bureau, China Earthquake Administration, employees health status, intervention measures, research.

Abstract. Employees' health is not only the basis of economic development enterprises, and is one of the ultimate goals of enterprise development.[1] Domestic and foreign health experts have a profound understanding of the protection of the health of key occupational groups, non-therapeutic sick workers, but rather treat the sick in the workplace. So with the occupational health promotion in recent years, more and more people get the supports of government, enterprises and institutions seriously.

\section{Introduction:}

Earthquake disaster do a serious harm to our country and people's lives, therefore, the party and government have always attached great importance to the work of the earthquake. Employees from China Earthquake Administration are keys to every work related to earthquake. [4] Therefore, it is necessary to carry out a series of occupational health survey for employees in China Seismological Bureau of Beijing area. Take the LUNG TB as an example, see chart A and chart B.

Chart A. The degree of LUNG TB of employees (male and female) from China Earthquake Administration (Beijing area).

\begin{tabular}{|c|l|l|l|r|r|l|l|l|l|l|}
\hline & \multicolumn{3}{|c|}{$1973-1975$} & \multicolumn{2}{c|}{$1900-1992$} & \multicolumn{2}{|c|}{$2004-2012$} \\
\hline & Total & Male & $\begin{array}{l}\text { Femal } \\
\text { e }\end{array}$ & Total & Male & $\begin{array}{l}\text { Femal } \\
\text { e }\end{array}$ & Total & Male & $\begin{array}{l}\text { Femal } \\
\text { e }\end{array}$ \\
\hline $\begin{array}{c}\text { Severe ones } \\
(1 / 100000)\end{array}$ & 5.46 & 7.13 & 3.70 & 17.54 & 24.03 & 10.66 & 30.84 & 41.34 & 19.84 \\
\hline $\begin{array}{c}\text { Not serious ones } \\
(1 / 100000)\end{array}$ & 8.76 & $\begin{array}{l}12.4 \\
6\end{array}$ & 4.52 & 20.84 & 26.30 & 16.04 & 36.47 & 40.37 & 21.52 \\
\hline
\end{tabular}

Chart B. The rate of LUNG TB of employees (male and female) with different age from China Earthquake Administration (Beijing area). (1/100000)

\begin{tabular}{|c|c|l|l|r|r|r|r|r|l|}
\hline Age groups & \multicolumn{3}{|l}{$1973-1975$} & \multicolumn{3}{|c|}{$1900-1992$} & \multicolumn{2}{|c|}{$2004-2012$} \\
\hline & Total & Male & Female & Total & Male & Female & Total & Male & $\begin{array}{l}\text { Femal } \\
\mathrm{e}\end{array}$ \\
\hline $22-29$ & 1.52 & 3.03 & 1.29 & 4.37 & 7.87 & 5.42 & 12.30 & 15.49 & 9.47 \\
\hline $30-45$ & 11.74 & 17.57 & 10.92 & 21.97 & 28.64 & 17.98 & 39.46 & 42.52 & 30.03 \\
\hline $45-60$ & 22.56 & 27.68 & 19.36 & 31.24 & 37.87 & 26.54 & 65.41 & 72.13 & 52.34 \\
\hline
\end{tabular}

From chart A and chart B, we can conclude that with time flying and age growing, the disaster rate of China Earthquake Administration of Beijing area is increasing speedily. Therefore, this survey for their health status and measures for innervations is allowing of no excuse. 


\section{Objective:}

To implement occupational health promotion for China seismological bureau of Beijing area, targeted suggestions are put forward.

\section{Methods:}

This paper comprehensively analyzes the health status results of employees from China seismological bureau of Beijing area. To carry out the occupational health survey results and improve the health level of worker, comprehensive intervention measures have to be taken, which include:

(1) To strengthen leadership, and increase community actions;

(2) To draw up healthy policies for employees in China seismological bureau of Beijing area, and to strengthen inspection work;

(3) To improve self-care skill of workers in diversified forms;

(4) To create a supportive environment, maintenance workers' health.

Sound corporate health surveys and promotion programs help to improve the health of workers, which are able to lay the foundation for health education implementation, monitoring and evaluation of results in the future. [3]

\section{Research purposes:}

1.Baseline investigation about the present situation of occupational health of the enterprise, finding out the problems existing in the enterprise the main occupational health; 2.Combined with the staff occupational health needs of content and form, to carry out the occupational health promotion interventions and preliminary evaluation on the effect.

2. Determined on the basis of the enterprise direction and improvement measures, the next step to carry out health promotion for the occupational health and promote the effect of the implementation, monitoring and evaluation of foundation, to build complete occupational health promotion engineering system. [4]

\section{The object of study:}

The workplace is the China Earthquake Administration of Beijing area, and 16 staff working in the existence of poisonous and harmful material, while 20 staff in occupational noise hazards workplace, as well as all the 291 employees. [5]

\section{Research methods:}

About the present situation of the enterprise existing occupational hazards evaluation report, the occupational-disease-inductive factors regular physical examination and test results, hires the annual health monitoring results, environmental protection monitoring data analysis evaluation, find out the enterprise the main occupational health hazards. [2]

At the beginning of the study using homemade enterprise group HSE training demand survey questionnaire, employee safety and health requirements and satisfaction survey, and Beijing health education provided by the factory, enterprise cadre, worker health knowledge questionnaire "baseline survey was conducted among 291 employees of the enterprise. [1]

Occupation health interventions are carried out according to the results of the survey, design and planning.

In the late study in the same questionnaire to survey the staff again, it is necessary to develop the preliminary evaluation on the effect of occupational health promotion measures.

The results are according to SPSS11.0 standard for sorting and analyzing. [1]

\section{The results of the study:}

The occupational health hazards factors of China Earthquake Administration is mainly as noise.

The employees of occupational health interventions demand results in the percentage of the content of the description, which is as follow: 
(1) $100 \%$ of the respondents have a healthy lifestyle includes diet to promote demand;

(2) $96.2 \%$ of the respondents demand for their own understanding related laws and regulations;

(3) $91.7 \%$ of the respondents have occupational hazard factors and the impact on the health information needs;

(4) $85.9 \%$ of the respondents have first aid and emergency rescue method needs;

(5) $79.0 \%$ of respondents is close to the demand to the company rules and regulations;

(6) $75.6 \%$ of respondents to labor hygiene knowledge and cognitive needs;

(7) $74.9 \%$ of occupational hazard protection knowledge needs;

(8) $72.2 \%$ of the fire protection knowledge demand, etc. [3]

The staff of occupational health interventions in the form of demand relatively tend to be informal occupational health promotion measures are taken, such as $96.2 \%$ of the employees choose knowledge contest, sports games was the choice for $81.4 \%$ of employees, etc. Agree to take formal training education employees accounted for $72.2 \%$. [4]

In this study conducted by the occupational health promotion interventions before and after the enterprise staff noise awareness of occupational hazard factors rising from $39.7 \%$ at the beginning of the study to the study of the late $94.1 \%$, labor insurance supplies utilization rate from $69.9 \%$ to $87.8 \%$ of late, and at the beginning of the study period at the end of the difference has statistical significance. [4]

Employee safety and health needs and satisfaction survey remained at a high employee satisfaction levels before and after the intervention, the average satisfaction was 83.56 and 89.99 respectively. [2]The difference was statistically significant between them, with the development of occupational health promotion interventions to employees of the enterprise safety health and job satisfaction will increase.

This study in general health promotion interventions at the same time, employees' health knowledge average scores at the beginning of the study was 75.13, in the late study scored an average of 85.6, at the beginning of the study and the end of the average score differences statistically significant health knowledge, after intervention the employee's health knowledge level are improved significantly. Smoking rates down from $12 \%$ at the beginning of the study at the same time to the study of the late $7.9 \%$, drunken rate from $24.7 \%$ at the beginning of the study have fallen to $9.2 \%$ of the late research. [3]

\section{Conclusions}

1. China earthquake Administration of Beijing area has good production conditions and working environment, and occupational hazard factors obtained the very good control, will have great influence to the health of employees.

2. The institute of occupational health promotion interventions can significantly improve the level of employees' occupational health knowledge, promote health behavior formation, and improve employee satisfaction.

3. The future of China earthquake Administration of Beijing area should be set up and improve the occupational health promotion goals and evaluation system on the basis of further broadening the scope and content of occupational health promotion for different people in different occupational health promotion.

Bearing in mind that work processes and working conditions become more and more stress organic. One can expect that in the near future health promotion interventions will form a group of the most dangerous hazards to work. Therefore, it is an urgent challenge facing the occupational health service (OHS) to adapt its system of prevention to the specificity of threats, and thus better protect employees against harmful impact.

\section{Acknowledgements}

supported by Science Research Fund for Teachers of China Seismological Bureau. 20110132 


\section{References}

[1] Du hanjiang, “The National Fitness' and 'Medical Prevention'” [J], China Sports Science and Technology Press, 2002. 8.

[2] Zhang xiaorong, “The Private Enterprise Employees' Psychological health condition investigation and invention", [M] Northwest Normal University Press, 2008-6.

[3] . Edwin. P. Hollander, "Principle and method of social psychology" [M], Guangdong Education Publishing House, 2009.

[4] Lewis. R, Gomez. Mejia. "Human resource management (fifth edition)", The Peking University Publishing House, 2011-6.

[5] Lu zhongjia, Huangpeihua, "Seismic geology introductory tutorial", Earthquake Publish Company, 1991, PP 34-58. 